\title{
A single center experience with minimally invasive approaches in congenital cardiac surgery
}

\author{
Joseph R. Nellis ${ }^{1,2}$, Mani A. Daneshmand ${ }^{1,3}$, Jeffrey G. Gaca ${ }^{1,3}$, Nicholas D. Andersen ${ }^{1,2,3,4}$, \\ John C. Haney ${ }^{1,3}$, Joseph W. Turek ${ }^{1,2,3,4}$
}

${ }^{1}$ Department of Surgery, Duke University, Durham, NC, USA; ${ }^{2}$ Duke Congenital Heart Surgery Research \& Training Laboratory, Durham, NC, USA; ${ }^{3}$ Division of Thoracic and Cardiovascular Surgery, Duke University, Durham, NC, USA; ${ }^{4}$ Pediatric \& Congenital Heart Center, Duke Children's Hospital, Durham, NC, USA

Contributions: (I) Conception and design: MA Daneshmand, JG Gaca, ND Andersen, JC Haney, JW Turek; (II) Administrative support: JR Nellis, ND Andersen, JW Turek; (III) Provision of study materials or patients: MA Daneshmand, JG Gaca, ND Andersen, JC Haney, JW Turek; (IV) Collection and assembly of data: JR Nellis; (V) Data analysis and interpretation: JR Nellis, JW Turek; (VI) Manuscript writing: All authors; (VII) Final approval of manuscript: All authors.

Correspondence to: Joseph W. Turek, MD, PhD, MBA. Division of Thoracic and Cardiovascular Surgery, Department of Surgery, Duke University Hospital, 2301 Erwin Road, DUMC 3474, Durham, NC 27710, USA. Email: joseph.turek@duke.edu.

Background: Cardiac surgery is a technically demanding field with an appreciable learning curve that extends beyond formal training. Minimally invasive congenital cardiac surgery has one of the steepest learning curves. Early complications often discourage surgeons, particularly those at lower volume centers, from pursuing innovative approaches. Over the past three years, we have utilized a number of minimally invasive approaches including pulmonary valve replacement, anomalous aortic origin coronary artery repair, atrial septal defect repair, epicardial lead placement, and partial anomalous pulmonary venous return. Herein we report on our experience performing minimally invasive congenital cardiac surgery, lessons learned, and how our approach has evolved.

Methods: We performed a single institution, retrospective review, wherein continuous variables were reported as median (interquartile range).

Results: Between September 2017 and May 2020, minimally invasive approaches were attempted on 49 patients with a median age of 19 years (14-47 years) for nine distinct congenital cardiac diagnoses. Seven patients (14\%) required conversion to larger incisions, including four patients or $36 \%$ of those undergoing anomalous aortic origin of a coronary artery repair. Patients who were converted had a higher body mass index 33.1 (31.7-37.8) than those who were not (24.2, 20.8-29.3) ( $\mathrm{P}=0.009)$.

Conclusions: Minimally invasive approaches for congenital cardiac conditions require a team approach. Patients with a body mass index greater than 30 should be counseled on the higher rate of conversion. We no longer perform minimally invasive anomalous aortic origin of a coronary artery repair given the high rate of conversions and complications. Surgeons attempting this procedure should do so cautiously.

Keywords: Congenital cardiac; minimally invasive; learning curve; pulmonary valve replacement; anomalous aortic origin of a coronary artery

Submitted May 15, 2021. Accepted for publication Jul 14, 2021.

doi: $10.21037 /$ jtd-21-836

View this article at: https://dx.doi.org/10.21037/jtd-21-836

\section{Introduction}

While the benefits of minimally invasive cardiac surgery are well established, so too are the disadvantages, including longer operative, bypass, and cross-clamp times $(1,2)$. Cardiac surgery is a technically demanding field, with a learning curve that extends far beyond formal training (3-6). 
For minimally invasive and congenital cardiac surgery, this learning curve is even more pronounced (4-7). Unfortunately, due to the lack of operative volume, early mentorship, or organizational support, some surgeons may never overcome the learning curve $(4,8,9)$. Furthermore, centers reporting innovative techniques face an uphill battle, as their early series often reflect these early complications (e.g., higher conversion rates, longer operative times, or no improvement in postoperative length of stay) (10-13). These surgeon or hospital-centric measures often overshadow the benefits these approaches provide to the patient, and discourage many surgeons from continuing to pursue these repairs despite their promise $(6,10,14)$.

Over the past three years, we have been utilizing a number of minimally invasive approaches for both adult and pediatric congenital cardiac surgery at our institution (15-19). All of our approaches started with the patient. During initial consultations and postoperative visits, patients often expressed concern about having surgery. For patients with a history of prior cardiac surgery, the concerns were centered around the recovery process, healing, and potential complications. Conversations with patients who had never had cardiac surgery often focused on the size of the incision, what to expect postoperatively, and the recovery process. After discussing these concerns with our adult thoracic and cardiac colleagues, we agreed to attempt a series of minimally invasive adult techniques for pulmonary insufficiency, anomalous aortic origin of coronary artery, atrial septal defects, partial anomalous pulmonary venous return, and a number of other congenital cardiac defects.

Herein we will describe the different approaches we have utilized, our outcomes, what has worked well, and what we have changed in accordance with the STROBE reporting checklist. The goal of this paper is to share our experience, in the hopes that others can learn from our mistakes, and we can improve upon the learning curve together.

We present the following article in accordance with the STROBE reporting checklist (available at https://dx.doi. org/10.21037/jtd-21-836).

\section{Methods}

\section{Patient selection}

We only offered minimally invasive approaches to low-risk patients in the beginning. At the time of initial consultation, the risks and benefits were clearly stated and patients were aware that we had only performed a limited number of these approaches for the given diagnosis. Patients were aware that their minimally invasive procedure may be converted to a standard incision, if the case was not progressing or it was no longer safe to continue through a limited field.

\section{Surgical technique}

To mitigate the risks of a new approach, all index cases were performed with the assistance of our adult cardiothoracic surgery colleagues. Only surgical approaches which provided rapid conversion to larger exposures were attempted. Cardiopulmonary bypass was performed peripherally, when required, except in the case of anomalous coronary repairs which were completed through a central cannulation strategy. To decrease the incidence of femoral artery pseudoaneurysms and distal limb ischemia due to peripheral cannulation, the arterial limb of the bypass circuit was always established to the femoral artery through a $6 \mathrm{~mm}$ end-to-side Dacron graft. Postoperatively, the femoral arteriotomy was repair with commercially available bovine pericardium.

The operative techniques for the included procedures have been previously described (15-19). Briefly, videoassisted thoracic surgery (VATS) atrial and ventricular sew-on epicardial lead placement was carried out with the patient in the right or left lateral decubitus position based on the intended procedure. Retraction, instrumentation, and visualization were obtained through three $5 \mathrm{~mm}$ thoracoscopic ports in fifth, seventh, and ninth intercostal spaces along the posterior axillary line.

Preoperative echocardiography was obtained for all patients undergoing intracardiac operations to evaluate for the presence of a patent foramen ovale. Procedures performed through left and right anterior mini-incisions were carried out through $5 \mathrm{~cm}$ incisions located in the $2 \mathrm{nd}$ or 3rd intercostal space based on preoperative imaging. Rib disarticulation was only necessary for patients undergoing anomalous coronary repair. Atrial septal defects and partial anomalous pulmonary venous return repairs were carried out through $5 \mathrm{~cm}$ right sub-mammary incisions. Early cardiopulmonary bypass allowed for decompression of the central vessels, facilitating the dissection. The pericardium was then opened, and the respective repairs were carried out. Fibrillation or cardiac arrest using del Nido cardioplegia solution were utilized, if repairs could not be accomplished with a beating heart. Key learning points, including how we have improved our surgical technique are listed in the Results. 


\section{Ethical considerations}

The study was conducted in accordance with the Declaration of Helsinki (as revised in 2013). This retrospective chart

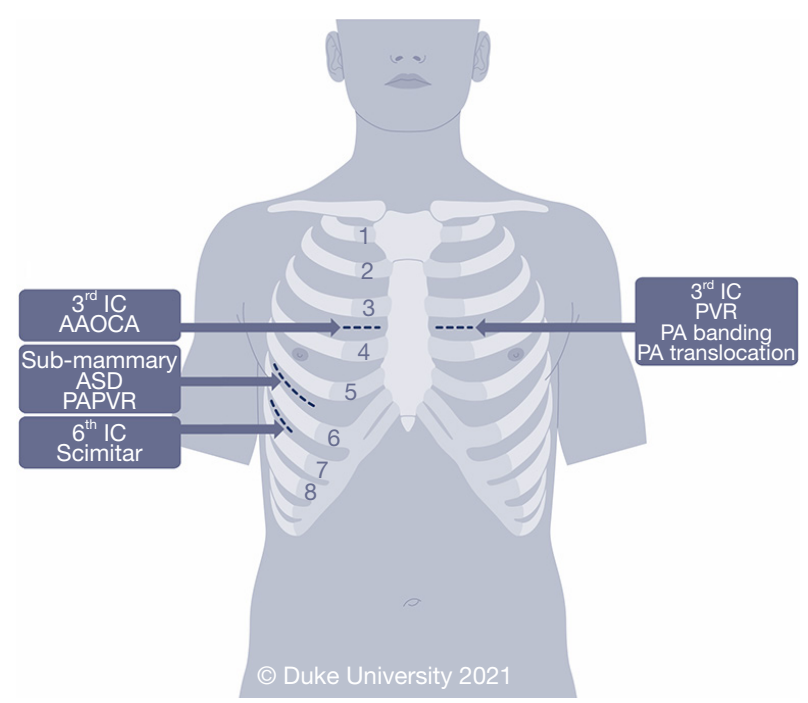

Figure 1 Minimally invasive approach by procedure. Graphical representation of various incisions including pulmonary valve replacement (PVR), pulmonary artery (PA) banding, PA translocation, anomalous aortic origin of a coronary artery (AAOCA), atrial septal defect (ASD), partial anomalous pulmonary venous return (PAPVR), and Scimitar syndrome. review was approved by institutional review board at Duke University (Pro00101549). Individual consent for this retrospective analysis was waived.

\section{Statistical analysis}

Descriptive statistics were used to characterize the collected data. Continuous variables are presented as medians and interquartile ranges (IQR), while categorical variables are presented as frequencies and raw counts. Continuous variables, where appropriate, were compared using KruskalWallis non-parametric analysis and categorical variables were compared using Fisher's exact test. A P value of less than 0.05 was defined as statistically significant. All statistical analyses were completed with SAS version 9.4 (SAS Institutes, Cary, NC, USA).

\section{Results}

\section{Preoperative characteristics}

Between September 2017 and May 2020, 49 patients with a median age of 19 years (IQR 14-47 years), underwent minimally invasive cardiac surgery for a congenital diagnosis. The most common indication for surgery was pulmonary insufficiency (30\%), anomalous aortic origin coronary artery (24\%), and atrial septal defect (20\%) (Figure 1, Tables 1-3). The median BMI was 24.8 (IQR 20.8-31.4), and 19 patients

Table 1 Characteristics of patients undergoing repair through a left anterior mini-incisions by procedure

\begin{tabular}{|c|c|c|c|c|c|}
\hline Operation & All procedures & PVR & PA banding & $\begin{array}{c}\text { Fibroelastoma } \\
\text { resection }\end{array}$ & $\begin{array}{l}\text { Pulmonary artery } \\
\text { translocation }\end{array}$ \\
\hline & 18 & 14 & 2 & 1 & 1 \\
\hline Age (years) & $17.5[13.3-52.5]$ & $16[13-25.7]$ & $61.5[59.7-63.3]$ & 55 & 15 \\
\hline Male & $13(72 \%)$ & $11(79 \%)$ & $1(50 \%)$ & 0 & 1 \\
\hline Number of prior sternotomies & $1[1-2]$ & $1[1-2]$ & $1[1-2]$ & 0 & 0 \\
\hline Converted to sternotomy & $2(11 \%)$ & $2(14 \%)$ & 0 & 0 & 0 \\
\hline Operative time (min) & 300 [281-340] & 315 [295-367] & 253 [234-272] & 202 & 286 \\
\hline Cardiopulmonary bypass time (min) & $137[121-151]$ & $139[128-154]$ & - & 40 & 57 \\
\hline Postoperative reintervention & - & - & - & - & - \\
\hline
\end{tabular}

BMI, body mass index; PVR, pulmonary valve replacement; PA pulmonary artery. 
Table 2 Characteristics of patients undergoing repair through a right anterior mini-incisions by procedure

\begin{tabular}{lc}
\hline Operation & AAOCA \\
\hline Number of operations performed & 11 \\
Age (years) & $30[17-49.5]$ \\
Male & $7(64 \%)$ \\
BMl & $25.5[23.7-36.3]$ \\
Number of prior sternotomies & - \\
Converted to sternotomy & $4(36 \%)$ \\
Operative time (min) & $285[218-300]$ \\
Cardiopulmonary bypass time (min) & $112[75-134]$ \\
Aortic cross clamp time (min) & $71[60-83]$ \\
Postoperative length of Stay (days) & $5[4-5.5]$ \\
Time to follow-up (days) & $407[197-525]$ \\
Postoperative reintervention & $2(18 \%)$ \\
\hline
\end{tabular}

One patient required coronary artery bypass on postoperative day 335 for angina secondary to competitive flow through collaterals and an occluded right coronary artery distal to the neo-ostium. A second patient required multiple sternal debridements and omental flap creation for mediastinitis after being converted to a median sternotomy during left anomalous aortic origin of a coronary artery repair. BMI, body mass index; AAOCA, anomalous aortic origin of a coronary artery.
(38\%) had previously undergone one median sternotomy (IQR 1-2.5).

\section{Operative characteristics and outcomes}

Forty-two patients (86\%) were successfully treated using a minimally invasive approach. The median operative time, cardiopulmonary bypass time, and cross-clamp time by successful minimally invasive procedure are listed in Tables 1-3. Cardiopulmonary bypass times for surgeries performed three or more times remained stable or down-trended over time except for minimally invasive anomalous aortic origin of a coronary artery (AAOCA) repairs (Figure 2). At a median follow up of 291 days (IQR 107-483 days), there are no reports of phrenic nerve injury or musculoskeletal impairment, and patients undergoing VATS sew-on epicardial lead placement continued to demonstrate stable lead sensitivity and impedance (16).

Two patients, who previously underwent a successful minimally invasive repair, required unplanned postoperative reinterventions. One patient required coronary artery bypass on postoperative day 335 for stable angina following neo-ostial creation for a right AAOCA. At the time of his original repair, there was satisfactory flow through the neo-

Table 3 Characteristics of patients undergoing repair through a right sub-mammary incision by procedure

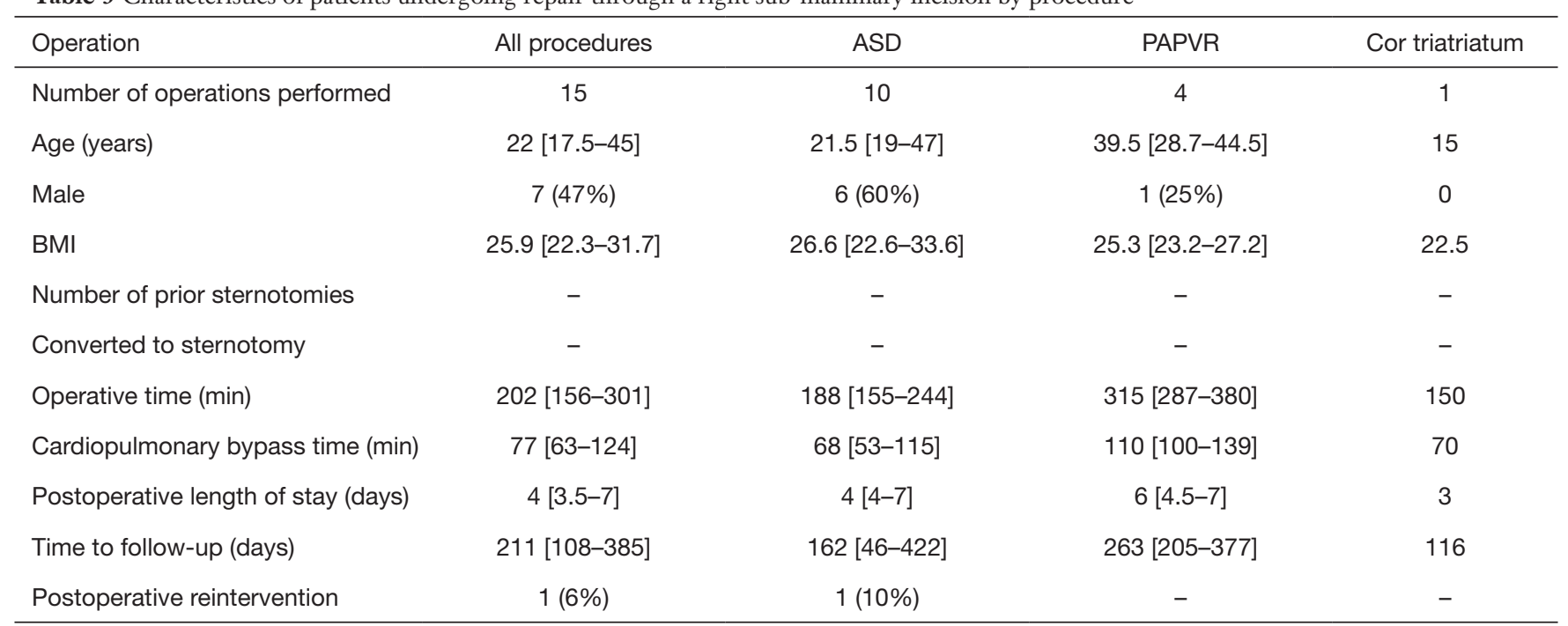

One patient with history of poorly controlled diabetes required groin and right sub-mammary incision washout with negative pressure wound therapy on postoperative day 23 following atrial septal defect repair for surgical site infections. BMI, body mass index; ASD, atrial septal defect; PAPVR, partial anomalous pulmonary venous return. 


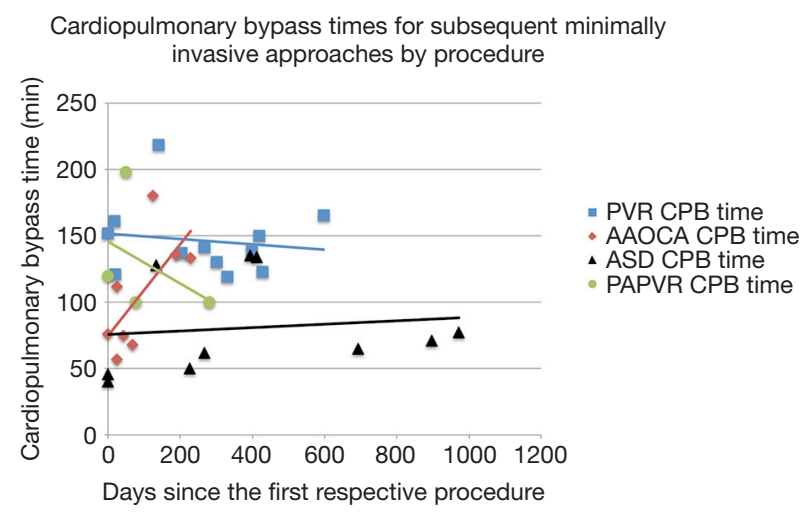

Figure 2 Cardiopulmonary bypass times for subsequent minimally invasive approaches by procedure. Graphical representation of cardiopulmonary bypass (CPB) times following the first minimally invasive pulmonary valve replacement (PVR) following tetralogy of Fallot repair, anomalous aortic origin of a coronary artery (AAOCA) repair, atrial septal defect (ASD) repair, and partial anomalous pulmonary venous return (PAPVR) repair. Cases are displayed by procedure and sequentially in days ( $\mathrm{x}$-axis) since the first minimally invasive repair was attempted. Trends in cardiopulmonary bypass times by procedure are displayed using linear regression.

ostia despite extensive collaterals within the proximal RCA. The patient did well postoperatively, although anginal symptoms were reported on postoperative day 318. Cardiac catheterization on postoperative day 320 showed increased collaterals, competitive flow, and areas of occlusion in segments one and two. Therefore, the patient underwent ligation and bypass through a median sternotomy. The second patient had a history of poorly controlled diabetes (preoperative hemoglobin A1c of 10\%) and developed surgical site infections at her groin cannulation site and right sub-mammary incision following minimally invasive atrial septal defect repair. She ultimately required eleven operative takebacks for wound debridement and negative pressure dressing changes between postoperative days 23 and 60 .

\section{Conversion to open operation}

Seven patients (14\%) were converted from a minimally invasive approach to a larger incision. Four patients, or $36 \%$ of those undergoing AAOCA repair through a right anterior mini-incision, were converted for difficult exposures or the need to perform coronary reimplantation. Two patients with tetralogy of Fallot, 14\% of those undergoing pulmonary valve replacement through a left anterior mini-incision, were converted due to foreseeable patient factors. One patient had mesocardia and his pulmonary valve couldn't be lateralized to meet the exposure. The other patient had previously underwent three median sternotomies including one for a pulmonary valve replacement. Due to a densely adherent infundibular patch, the case was converted. The last patient, with a history of hypoplastic left heart and three prior median sternotomies, was converted to a $7 \mathrm{~cm}$ thoracotomy during a VATS sew-on epicardial lead placement secondary to dense adhesions.

Weight and BMI were factors associated with procedures being converted to open. Briefly, patients who were converted weighed $103 \mathrm{~kg}$ (IQR 99-105 kg), while those successfully undergoing minimally invasive repair weighed $67.8 \mathrm{~kg}$ (IQR $58.2-85.3 \mathrm{~kg})(\mathrm{P}=0.011)$. BMI better characterizes the two groups, wherein patients who were converted had a median BMI of 33.1 (IQR 31.7-37.8) while those undergoing a minimally invasive repair had a median BMI of 24.2 (IQR 20.8-29.3) ( $\mathrm{P}=0.009)$. No differences were observed between the groups with regards to patient age, gender, or the number of prior median sternotomies $(\mathrm{P}=0.078,1.0$, and 0.931 , respectively).

At a median 356 days follow-up (IQR 248-549 days), one patient experienced a complication. She had previously undergone conversion to median sternotomy for left AAOCA repair due to a BMI of 39 and inadequate exposure. She developed mediastinitis and ultimately required five operative debridements and an omental flap for coverage.

\section{Discussion}

Every cardiac surgeon understands that practice makes perfect. From standard valve replacements to minimally invasive techniques, a learning curve exists (3-5). With the exception of coronary artery bypass procedures, bypass and cross-clamp times improve over a surgeons' career (3). For minimally invasive mitral, the effect is even more pronounced. According to Holzhey et al. and others, surgeons need to do at least one minimally invasive mitral a week and a minimum of 60 to 125 cases, before they overcome the learning curve $(4,6)$. In congenital cardiac surgery, the volume-outcomes relationship is also well established, with one in four operative mortalities being attributed to children being operated on at a lower volume center (9). It follows then that minimally invasive congenital cardiac approaches may have the steepest learning curve, hindered by both volume and frequency.

Successful minimally invasive congenital cardiac surgery 
requires a team approach. As previously mentioned, cross collaboration with our adult thoracic and cardiac colleagues helped accelerate our learning curve, but the team should also include those outside one's institution $(20,21)$. We performed our operations at a high volume center with the assistance of our adult colleagues who specialize in these minimally invasive approaches. Despite these advantages, we were not immune to the learning curve, experiencing a number of complications and conversions. In our opinion, the learning curve is deeply founded in the mechanical familiarity associated with these nuanced approaches. Insights alone are not sufficient to solve this learning curve, but they will improve the process for us all, if we share our early experiences and have this conversation in a public forum.

The risks and benefits of a new approach should only pertain to the patient. New approaches are intimidating. While we know the anatomy, have read about the technique, and may have seen a video, the fear of failure remains. This is important if the risks pertain to the patient, but should be disregarded if they are irrational, or only affect the surgeon (e.g., cardiopulmonary bypass or operative times). Furthermore, surgeons should understand that there will be complications along the way. This is the learning curve, and it is expected. We did not always deliver on our promise to patients, and through these experiences we refined our selection criteria, technique, and willingness to offer certain procedures again.

Today, we are more selective in who we offer minimally invasive congenital cardiac surgery to. While we want to help patients avoid sternal precautions, get out of the hospital faster, and have smaller scars, it shouldn't come at the integrity of the repair. VATS sew-on epicardial leads are still offered to patients who require external dualchambering pacing. Despite one conversion for adhesions, previous cases in patients with prior sternotomies were successfully completed, therefore we do not consider this a contraindication for the approach. We do not see a large number of these cases, but continue to offer it as an option for patients and referring providers. Left anterior miniincisions for pulmonary artery and valvular anomalies are selectively offered to patients with BMIs $>30$. At this time, we continue to offer sub-mammary ASD and PAPVR repairs to everyone, although we are cautious with patients who present with high anomalous veins. While the approach works for these patients, it is noticeably more challenging. Lastly, we have come to realize that a limited right anterior mini-incision for the repair of anomalous aortic origin coronary arteries may not be an appropriate exposure for patients requiring coronary reimplantation or bypass. Preoperative imaging helps confirm the diagnosis of an anomalous aortic origin coronary, but the necessary repair is not always known until the aorta is opened. This has led to a higher conversion rate than we would like, so we are reluctant to offer this approach any longer.

To those attempting these procedures, we would encourage review of the literature, particularly with regards to the technical nuances (15-19). In our experience, preoperative imaging helps guide the final incision placement for minimally invasive cases. This includes ultrasound assessment of the femoral vessels prior to making an incision, in order to avoid unnecessarily starting a minimally invasive incision when peripheral bypass is not an option. When peripheral cannulation is used, we always establish our arterial connection using a $6 \mathrm{~mm}$ Dacron graft in an end-to-side fashion. This is a technique that is critical for smaller pediatric patients, but one we've carried over for all of our cases, including adults. For patients undergoing minimally invasive pulmonary valve replacement, wound protectors improve the exposure. Additionally, we have found that the valve sits better when secured inferiorly from the right ventricular outflow tract using a commercially available suture fastener. From our minimally invasive submammary experience, we have attempted repairs while fibrillating and with the heart arrested. The decision continues to be surgeon preference. And while high PAPVR and Warden procedures are possible through this approach, they are incrementally more difficult and may not be ideal for this type of incision.

A single institution, retrospective review with low sample size and high operative heterogeneity carries a number of limitations. First and foremost, patient selection was key, particularly early on for each individual approach. The study was retrospective and did not randomize patients to an approach. The small sample size also limited our ability to make meaningful conclusions at the individual procedure level. While previous reports have described the technical challenges with each minimally invasive operation, we focused on the different exposures and our results may not be generalizable. Surgeons at our institution were very comfortable operating through a limited field, which may also bias our results and the likelihood of success for those attempting similar approaches based on our experience.

In conclusion, patients stand to benefit from innovative approaches in congenital cardiac surgery. These approaches should always be developed with the patient first, and 
surgeons should understand that a learning curve exists. Complications will occur and patients should be aware of these risks preoperatively, as well as the likelihood of conversion to larger, more traditional, incisions. Performance should be evaluated on a case-by-case basis, and approaches judged based on their potential. By sharing our collective experience in a public forum, we can get the honest feedback necessary to safely push the boundaries in congenital cardiac surgery and improve outcomes together.

\section{Acknowledgments}

Funding: None.

\section{Footnote}

Reporting Checklist: The authors have completed the STROBE reporting checklist. Available at https://dx.doi. org/10.21037/jtd-21-836

Data Sharing Statement: Available at https://dx.doi. org/10.21037/jtd-21-836

Peer Review File: Available at https://dx.doi.org/10.21037/ jtd-21-836

Conflicts of Interest: All authors have completed the ICM$\mathrm{JE}$ uniform disclosure form (available at https://dx.doi. org/10.21037/jtd-21-836). Dr. JWT serves as an unpaid editorial board member of Fournal of Thoracic Disease. The other authors have no conflicts of interest to declare.

Ethical Statement: The authors are accountable for all aspects of the work in ensuring that questions related to the accuracy or integrity of any part of the work are appropriately investigated and resolved. The study was conducted in accordance with the Declaration of Helsinki (as revised in 2013). The study was approved by institutional review board at Duke University (Pro00101549). Individual consent for this retrospective analysis was waived.

Open Access Statement: This is an Open Access article distributed in accordance with the Creative Commons Attribution-NonCommercial-NoDerivs 4.0 International License (CC BY-NC-ND 4.0), which permits the noncommercial replication and distribution of the article with the strict proviso that no changes or edits are made and the original work is properly cited (including links to both the formal publication through the relevant DOI and the license). See: https://creativecommons.org/licenses/by-nc-nd/4.0/.

\section{References}

1. Cheng DC, Martin J, Lal A, et al. Minimally invasive versus conventional open mitral valve surgery: a metaanalysis and systematic review. Innovations (Phila) 2011;6:84-103.

2. Van Praet KM, Stamm C, Sündermann SH, et al. Minimally Invasive Surgical Mitral Valve Repair: State of the Art Review. Interv Cardiol 2018;13:14-9.

3. Burt BM, ElBardissi AW, Huckman RS, et al. Influence of experience and the surgical learning curve on long-term patient outcomes in cardiac surgery. J Thorac Cardiovasc Surg 2015;150:1061-7, 1068.e1-3.

4. Holzhey DM, Seeburger J, Misfeld M, et al. Learning minimally invasive mitral valve surgery: a cumulative sum sequential probability analysis of 3895 operations from a single high-volume center. Circulation 2013;128:483-91.

5. Nissen AP, Nguyen S, Abreu J, et al. The first 5 years: Building a minimally invasive valve program. J Thorac Cardiovasc Surg 2019;157:1958-65.

6. Vo AT, Nguyen DH, Van Hoang S, et al. Learning curve in minimally invasive mitral valve surgery: a single-center experience. J Cardiothorac Surg 2019;14:213.

7. Fraser CD. Becoming a congenital heart surgeon in the current era: Realistic expectations. J Thorac Cardiovasc Surg 2016;151:1496-7.

8. Karamlou T, Jacobs ML, Pasquali S, et al. Surgeon and center volume influence on outcomes after arterial switch operation: analysis of the STS Congenital Heart Surgery Database. Ann Thorac Surg 2014;98:904-11.

9. Austin JM, Derk JM, Pronoost PJ. An analysis of publically reported pediatric heart surgery data and patient mortality implications. J Hosp Manag Health Policy 2018;2:50.

10. Mohr FW, Falk V, Diegeler A, et al. Minimally invasive port-access mitral valve surgery. J Thorac Cardiovasc Surg 1998;115:567-74; discussion 574-6.

11. Alsarraj MK, Nellis JR, Vekstein AM, et al. Borrowing from Adult Cardiac Surgeons-Bringing Congenital Heart Surgery Up to Speed in the Minimally Invasive Era. Innovations (Phila) 2020;15:101-5.

12. Currie ME, Romsa J, Fox SA, et al. Long-term angiographic follow-up of robotic-assisted coronary artery revascularization. Ann Thorac Surg 2012;93:1426-31.

13. Loulmet D, Carpentier A, d'Attellis N, et al. Endoscopic coronary artery bypass grafting with the aid of robotic 
assisted instruments. J Thorac Cardiovasc Surg 1999;118:4-10.

14. Harold JG. Harold on history: the evolution of transcatheter aortic valve replacement. Cardiology Magazine. American College of Cardiology; 2017.

15. Nellis JR, Vekstein AM, Meza JM, et al. Left Anterior Mini-Incision for Pulmonary Valve Replacement Following Tetralogy of Fallot Repair. Innovations (Phila) 2020;15:106-10.

16. Nellis JR, Alsarraj MK, Sauer JS, et al. A minimally invasive approach for atrial and ventricular sew-on epicardial lead placement. JTCVS Tech 2021;7:245-8.

17. Nellis JR, Drysdale N, Evans M, et al. Anomalous aortic origin of a coronary artery repair through a minimally invasive anterior mini-thoracotomy. Innovations 2021. doi:
$10.1177 / 15569845211031541$.

18. Said SM. Minimally invasive pulmonary valve replacement via left anterior minithoracotomy. JTCVS Tech. 2020;6:127-9.

19. Nguyen TC. Minimally invasive ASD repair: step-bystep guide. CTSNet. February 2018. doi:10.25373/ ctsnet.5904877.

20. Turek JW, Ad N. Commentary: A synergy of two is better than one: Modern-day heart team approach to robotic congenital heart surgery. JTCVS Tech 2020;4:267-8.

21. Sef D, Wei LM, Rankin JS, et al. Robotic-assisted twopatch repair of right partial anomalous pulmonary venous connection and sinus venosus defect. JTCVS Tech 2020;4:262-4.

Cite this article as: Nellis JR, Daneshmand MA, Gaca JG, Andersen ND, Haney JC, Turek JW. A single center experience with minimally invasive approaches in congenital cardiac surgery. J Thorac Dis 2021;13(10):5818-5825. doi: 10.21037/ jtd-21-836 